\title{
TI.78.1
}

\section{Architecting Security}

- PDF: NERCOMP-Fall07-v09.pdf

- Text: NERCOMP-Fall07-v09.txt

\section{More Information}

\begin{tabular}{|c|c|}
\hline Repository ID & TI.78.1 \\
\hline Persistent URL & http://doi.org/10.26869/TI.78.1 \\
\hline Title & Architecting Security \\
\hline Authors & Mark Poepping \\
\hline Sponsor & SALSA \\
\hline \multicolumn{2}{|l|}{ Review } \\
\hline Status & Legacy \\
\hline Publish Date & $9 / 24 / 2007$ \\
\hline DOI & 10.26869/TI.78.1 \\
\hline \multicolumn{2}{|l|}{ Signature } \\
\hline Deprecated & No \\
\hline \multicolumn{2}{|l|}{ Future Review } \\
\hline \multicolumn{2}{|l|}{ Supersedes } \\
\hline Format & PDF, Text \\
\hline \multicolumn{2}{|l|}{ Related Docs } \\
\hline \multicolumn{2}{|l|}{ Development Location } \\
\hline \multicolumn{2}{|l|}{ IP Framework } \\
\hline Subject Tags & middlewarerescue \\
\hline Notes & \\
\hline
\end{tabular}

